\title{
The Implications of a South-South Customs Union on Tariffs, Welfare, and the Prospect of Global Free Trade*
}

\author{
Hiranya K. Nath \\ Sam Houston State University • Huntsville, Texas \\ Halis Murat Yildiz \\ Ryerson University • Toronto, Ontario
}

\begin{abstract}
Following the failure of multilateral trade negotiations at the Cancun meeting and the Doha Round, developing countries have pursued an alternative in socalled "south-south" trade agreements. Since these agreements lead to trade diversion from efficient north (developed) countries to less efficient south (developing) partners, there have been widespread concerns regarding their welfare implications. Using a three country oligopoly model of trade, we first examine statically the implications of a south-south customs union (CU) on the pattern of tariffs and welfare. We find that south countries always have incentives to form a $\mathrm{CU}$ that reduces the welfare of the north country. Moreover, when south firms are sufficiently inefficient relative to north firms, a south-south $\mathrm{CU}$ leads to a large trade diversion effect and reduces world welfare. We further show that, in a repeated interaction model, free trade is less likely to be sustainable under the south-south $\mathrm{CU}$ relative to no agreement.
\end{abstract}

\section{Introduction}

By permitting a group of member countries of the World Trade Organization (WTO) to form a preferential trade agreement (PTA) wherein these countries extend tariff concessions to each other but not to other WTO member countries, Article XXIV of the General Agreement on Tariffs and Trade (GATT) provides an important exception to the most-favored-nation (MFN) clause (contained in Article I of GATT). ${ }^{\prime}$ Since the notion of non-discrimination as specified by the MFN clause is at the heart of the WTO system, the existence of Article XXIV has not been without controversy. ${ }^{2}$ PTAs are so widespread today that MFN treatment appears to be more of an exception rather than a norm and, thus, far from playing a pivotal role in multilateral trade liberalization. According to the WTO (2009), there are over 200 PTAs in force today and almost all major countries participate in one or more PTAs of various types. Prominent examples of PTAs include the North American Free Trade Agreement (NAFTA), the South American Common Market (MERCOSUR), the Association of 
South East Asian Nations (ASEAN) Free Trade Area, the Andean Pact, and numerous agreements of the European Union with other countries.

The failure of multilateral trade negotiations at the Cancun meeting and the Doha Round led the developing countries to look for an alternative in so-called "south-south" PTAs. As Stiglitz (2003) argues, even though there is more to gain from North-South trade in theory, just as north-north trade agreements have intensified, there is no question that south-south trade agreements can also flourish. Bhagwati and Panagariya (1996), Ray (1998), and Das and Ghosh (2006) contend that the majority of the PTAs have been formed between similar countries (so-called north-north agreements between developed countries and south-south agreements between developing countries) rather than between developed and developing countries (north-south agreements).

This paper aims at addressing the following questions. What are the implications of a south-south customs union (CU) on the pattern of tariffs and the welfare of the member and non-member countries and the world as a whole? Do these agreements facilitate multilateral trade liberalization process? To address these questions, we develop a three-country oligopoly trade model with one north (developed) and two south (developing) countries. We begin with the premise that the north firms have a superior production technology compared to that of south firms. ${ }^{3}$ That the above questions are important is evident from the recent proliferation of PTAs between developing countries. As per WTO, the number of PTAs between developing countries has increased dramatically over the last two decades: 70 new such agreements have been formed between 1990 and 2003 and they account for more than 50 percent of all new trade agreements, including those not notified to the WTO. Important examples include MERCOSUR in South America, South Asia Free Trade Area (SAFTA), the Group of Three, and South Africa Customs Union (SACU). Recently, three major south countries: India, Brazil, and South Africa, have taken major steps leading to south-south cooperation.

In the literature, following Jacob Viner's (1950) classic analysis, economists as well as policy-makers have extensively discussed the static and dynamic distortions created by preferential trade liberalization. It has been argued that PTAs can lead to trade creation if member countries switch from inefficient domestic producers and import from more efficient producers in other member countries of the PTA. On the other hand, trade diversion takes place when member countries substitute efficient, low-cost imports from non-member countries with less efficient imports from member countries. The net welfare effect of a PTA depends upon which of these two effects dominate. Since south member countries substitute efficient im- 
ports from non-member north countries with less efficient imports from south partners, there has been widespread concern regarding the welfare implications of southsouth CU. Grossman and Helpman (1995) claim that the formation of trade diverting PTAs is the most likely case. Further, Schiff and Winters (2003) argue that a PTA between two small developing countries is likely to generate only trade diversion and no trade creation. The rationale for this argument is that the increased export profits in such a PTA stem mainly from trade diversion via an inefficient transfer of tariff revenue to the bloc's exporters. This argument is contested by Ornelas (2005) who shows that the exporting rents generated by exchanging preferential market access and coordinating external tariffs under a CU can offset trade diversion losses. It is important to note that Ornelas (2005) uses the same oligopoly set-up as here but assume that countries are completely symmetric with respect to production technology, but asymmetric with respect to market size. Unlike Ornelas (2005), we examine the dynamic implications of CUs on the multilateral tariff cooperation.

In order to tie our results with those in the existing literature, we first consider a two-stage static game. In the first stage, given the agreement in place, countries choose their optimal tariffs. Then, firms compete in a Cournot fashion. We find that, even when the external tariff of the member countries fall under $\mathrm{CU}$ relative to no agreement (tariff complementarity effect as required by Article XXIV of the GATT), the formation of a south-south $\mathrm{CU}$ reduces the welfare of the north country. Moreover, when south countries are sufficiently inefficient relative to the north, south-south agreement leads to a large trade diversion effect and thus reduces world welfare. By adding an initial stage to the above game where south countries decide whether to form a $\mathrm{CU}$ or not, we can show that south countries always have incentives to form a $\mathrm{CU}$ since they benefit from exchanging market access at the outsider's expense.

We then analyze infinite repetition of the above two-stage static game to allow countries to cooperate multilaterally over free trade and show that multilateral cooperation over free trade is less likely to be sustainable when south-south CU is formed relative to no agreement. These results suggest that, when the cost asymmetry across regions is sufficiently high, the concerns over the negative impact of a south-south $\mathrm{CU}$ on the world welfare and the prospect of global free trade are legitimate.

\section{Basic Model}

We develop a simple oligopoly model of trade in which each country has a unilateral incentive to impose rent extracting tariffs on those trading partners with 
whom it does not have any trade agreement. There are three countries: one is a north country $(n)$ and the other two are south countries ( $s$ and $\tilde{s}$ ). Two goods are produced in each country: $x$ and $y$. Good $x$ is produced by a single profit-maximizing firm in each country at a constant marginal cost in terms of the numeraire good $y$ that is produced under perfect competition with constant returns to scale technology. The gains from trade stem from reduced market power in the domestic industry. To this end, the monopoly assumption is not crucial but is the simplest way to represent market power. Note that, for notational simplicity, whenever we say firm $i$, it refers to country $i$ 's firm. The north and south countries are asymmetric with respect to their marginal costs of production. For simplicity, we assume that $c_{s}=c_{\tilde{s}}=c>c_{n}=0$. The assumption that marginal cost is constant implies that there is no advantage in establishing more than one plant. If marginal costs were rising, firms have the incentive to build several plants to serve the foreign markets. In order to exclude prohibitive cost levels and guarantee market access of south firms, we assume that $c \leq \frac{\alpha}{4}$ holds hereafter. Preferences over the two goods are quasilinear:

$$
U_{i}\left(x_{p} y_{i}\right)=u\left(x_{i}\right)+y_{i}
$$

Furthermore, $u\left(x_{i}\right)$ is assumed to be quadratic so that the demand curve for good $x$ is linear in country $i$ :

$$
p_{i}\left(x_{i}\right)=\alpha-\sum_{j} x_{j i}
$$

where $x_{j i}$ denotes the output sold by country $j$ 's firm in country $i$, while $x_{i}$ is the total output sold in country $i: x_{i} \equiv \sum_{j i} x_{j i}$ Note that $\alpha$ represents the reservation price for a representative consumer above which there is no demand for the non-numeraire good.

Next, we consider a two-stage static game that compares no agreement and a south-south CU with respect to external tariffs and welfare levels.

\section{Static Game}

We examine a two-stage game under two distinct trade regimes: no agreement $(\{\Phi\})$ and south-south CU ( $\{\mathrm{S}\})$. The game proceeds as follows. In the first stage, given the trade agreements, countries simultaneously choose their tariff schedules. Then, firms compete in a Cournot fashion in the product markets. We solve the above game backwards in order to obtain subgame perfect Nash equilibrium (SPNE). 


\section{No Agreement ( $\{\Phi\})$}

Since Article I of the GATT (the MFN Clause) forbids tariff discrimination, we restrict our attention to symmetric external tariffs by each country. Let $t_{i}^{\phi}$ be the tariff imposed by countries where $i=n, s, \tilde{s}$. Firms' effective marginal costs of exporting equal:

$$
c_{i j}=c_{i}+t_{j}^{\phi}, \text { for all } i \neq j
$$

Then, export profit functions can be written as:

$$
\pi_{i j}=\left[p_{j}\left(x_{j}\right)-c_{i j}\right] x_{i j} \text {, for all } i \neq j,
$$

where $\pi_{i j}$ denotes firm $i$ 's export profits in country $j$.

First order conditions (FOCs) for profit maximization for exporters are:

$$
p_{j}+p_{j}^{\prime} x_{i j}=c_{i j} \text {, for all } i \neq j \text {. }
$$

The above FOCs, together with an analogous condition for the local firm, can be easily solved for equilibrium output levels and profits: ${ }^{4}$

$$
\pi_{i j}=x_{i i}^{2}, \pi_{i j}=x_{i j}^{2}, \text { for all } i \neq j
$$

Due to the symmetric nature of south firms, we denote a typical south country (firm) by $s$ from hereon. The following comparative static results are standard:

$$
\frac{d x_{z i}}{d t_{i}^{\phi}}<0<\frac{d x_{i i}}{d t_{i}^{\phi}} ; \text { and } \frac{d x_{i}}{d t_{i}^{\phi}}<0 \text { where } z \neq i .
$$

In other words, a country's tariff lowers imports from other countries to its domestic market, increases the sales of its local firm, and lowers the total output sold in its market.

Welfare of country $i$ is defined as the sum of its domestic surplus and total export profits:

$$
w_{i} \equiv S_{i}+\sum_{j \neq i} \pi_{i j}
$$

where 


$$
S_{i} \equiv u\left(x_{i}\right)-p_{i} x_{i}+\pi_{i i}+t \sum_{j \neq i} x_{j i}
$$

Since markets are segmented, strategic independence of trade policies is obtained. Thus, country $i$ 's tariff choice problem reduces to:

$$
\max _{t_{i}} S_{i} \equiv u\left(x_{i}\right)-p_{t^{\prime}} x_{i}+\pi_{i i}+t_{i} \sum_{j \neq i^{\prime}} x_{j i^{\prime}}
$$

The optimal tariffs are given by

$$
t_{i}^{\phi}=\frac{3 \alpha-2 c}{10}
$$

\section{South-South $C U(\{S\})$}

Due to market segmentation, the north country solves the same problem as in (10) and thus imposes the same optimal tariff as under $(\{\Phi\}): t_{n}^{S}=t_{n}^{\phi}$. When south countries form a CU with each other, they abolish tariffs on each other and impose a common external tariff $\left(t_{s}^{5}\right)$ on north firm's export. Therefore, under $(\{S\})$, the problem in (10) is modified as follows:

$$
\max _{t_{s}}\left(w_{s}+\pi_{\Im s}\right)
$$

The following optimal tariff levels solve the above problem:

$$
t_{s}^{\mathcal{S}}=\frac{5 \alpha+2 c}{19}
$$

Under complete symmetry $(c=0)$, when south countries form a CU, export of the south member country increases while that of north non-member decreases. As a result, compared to $(\{\Phi\})$, south members' incentive to impose a tariff on the north non-member decreases since the north non-member country becomes a less important source for rent-extraction. This result is known as the tariff complementarity effect in the literature (see Bagwell \& Staiger, 1997, 1998). However, when cost of production is sufficiently asymmetric across regions, the tariff complementarity effect does not necessarily hold:

$$
t_{\frac{S}{s}}-t_{s}^{\phi} \geq 0 \text { iff } c \geq \frac{7 \alpha}{58} .
$$


It is important to note that in order to minimize the potential harmful effects of PTAs, Article XXIV requires that member countries should not raise tariffs on non-members relative to tariffs under no agreement. ${ }^{5}$ To this end, hereafter we assume that $t_{s}^{\mathcal{S}}=\frac{3 \alpha-2 c}{10}$ when $\mathrm{c}>\frac{7 \alpha}{58}$ holds. Based on these optimal tariffs, the comparison of welfare yields the following result: ${ }^{6}$

Proposition 1: Suppose that $c \leq \frac{\alpha}{4}$ holds. Then, the following results are obtained: (i) south countries always have an incentive to form a $C U$ with each other: $w_{s}(S)>w_{s}(\Phi)$ for all c; (ii) south-south $C U$ always reduces the welfare of north countries: $w_{n}(S)<w_{n}(\Phi)$ for all $c$, and (iii) world welfare is lower under $(\{\mathrm{S}\})$ relative to $(\{\Phi\})$ if the cost asymmetry is sufficiently large: $w w(S) \leq w w(\Phi)$ iff $c \geq c^{w w}=\frac{29 \alpha}{126}$.

The first part of the above proposition provides a support to the idea that, as north-north trade agreements have intensified, there is no question that south-south trade agreements can also flourish. In other words, south countries always have an incentive to form a CU excluding the efficient north country. The second part of the above proposition argues that the non-member country is worse off under $(\{\mathrm{S}\})$ relative to $(\{\Phi\})$ since while its domestic surplus stays unchanged, its firm is discriminated in each of the south country markets against its rival exporter. Finally, when the cost asymmetry across regions is sufficiently high, the concerns over the negative impact of such agreements on the world welfare are legitimate. The intuition behind the last part of the proposition is as follows. Since south member countries have free access in each other's market while the north country's firm faces an external tariff, they substitute efficient imports from the non-member north country with less efficient imports from south partners. As a result, trade diversion effect arises and it increases as the cost asymmetry rises. Thus, as represented in figure 1, world welfare is lower under $(\{S\})$ relative to $(\{\Phi\})$ when south firms are sufficiently inefficient relative to the north firm.

Next, we employ infinite repetition of this one-shot game in order to examine the implications of south-south $\mathrm{CU}$ on the prospect and sustainability of global free trade. 
Figure 1

World Welfare Comparison $(\alpha=1)$

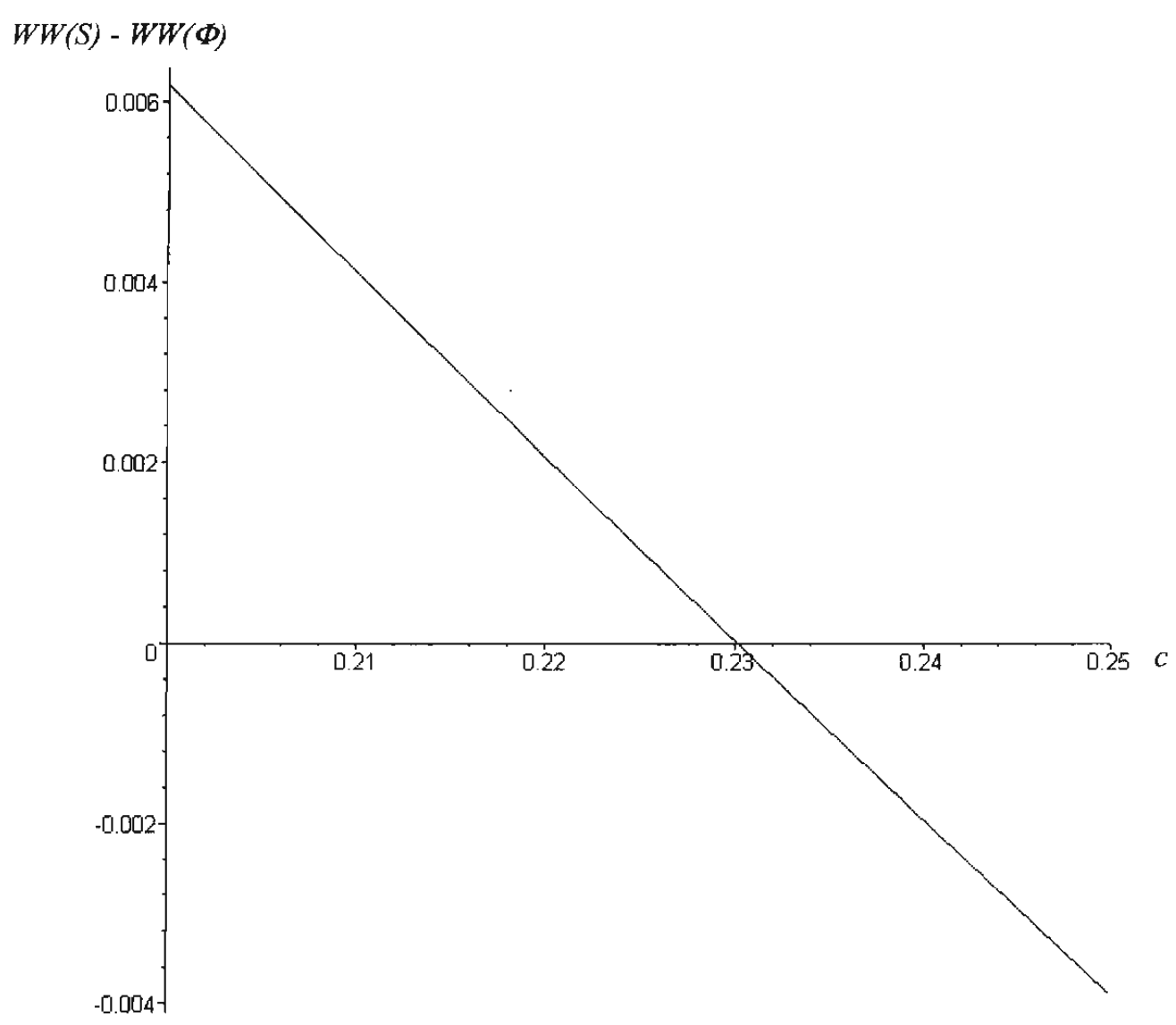

\section{Sustainability of Cooperation over Free Trade}

In order to determine whether multilateral cooperation over free trade under $(\{S\})$ is easier or harder to sustain relative to $(\{\Phi\})$, we analyze infinite repetition of the above one-shot game. As in Riezman (1991), Bagwell and Staiger (1997a, 1997b, 1998), Bond, Syropoulos, and Winters (2001), and Saggi (2006), such cooperation is required to be self-enforcing: each country balances the current benefit of deviating from the cooperative tariff against the future losses it suffers under the permanent trade war that results from its defection. Similar to Saggi (2006), we assume that $\mathrm{CU}$ is permanent by nature so that members retain zero tariffs on each other, even if cooperation with the non-member breaks down.

\section{Tariff Cooperation over Free Trade under $(\{\Phi\})$}

Suppose each country employs a zero tariff until someone defects, in which case cooperation breaks down with countries switching to their MFN tariffs forever. In order to proceed, it is useful to discuss the costs and benefits of multilateral 
cooperation for all countries. Under free trade, the per period welfare of a country equals:

$$
w_{i}^{F}(t=0) \equiv S_{i}\left(t_{i}=0\right)+\sum_{z \neq i} \pi_{i z}\left(t_{z}=0\right)
$$

Let $w_{i}^{D}\left(t_{i}^{\phi}, t_{z}=0\right)$ denote the welfare of a country that defects from free trade to its optimal tariff, $t_{i}^{\phi}$ :

$$
w_{i}^{D}\left(t_{i}^{\phi}, t_{z}=0\right) \equiv S_{i}\left(t_{i}^{\phi}\right)+\sum_{z \neq i} \pi_{i z}\left(t_{z}=0\right)
$$

It is immediate from the above equations that defection from free trade benefits the defecting country by increasing its domestic surplus through the ability to impose optimal tariffs. One period benefit from defection for south countries equals

$$
\begin{aligned}
& B_{s}(\Phi)=w_{s}^{D}\left(t_{s}^{\phi}, t_{z}=0\right)-w_{s}^{F}(t=0) \\
& =S_{s}\left(t^{\phi}\right)-S_{s}\left(t_{s}=0\right) \\
& =\frac{13 \alpha-2 c l^{2}}{I 60}>0, \text { where } z \neq s .
\end{aligned}
$$

Similarly, one period benefit from defection for the north country equals

$$
\begin{aligned}
& B_{n}(\Phi)=w_{n}^{D}\left(t_{n^{\prime}}^{\phi} t_{z}=0\right)-w_{n}^{F}(t=0) \\
& =S_{n}\left(t_{n}^{\phi}\right)-S_{n}\left(t_{n}=0\right) \\
& =\frac{13 \alpha-\left.2 c\right|^{2}}{160}>0, \text { where } z \neq n .
\end{aligned}
$$

It is important to note that one period benefit from defection falls as the degree of asymmetry between south and north firms rises:

$$
\frac{\partial B_{s}(\Phi)}{\partial c}=\frac{\partial B_{n}(\Phi)}{\partial c}<0
$$

Next, we consider the per period cost of defection. When cooperation breaks down, from next period on, countries use their MFN tariffs. The per period cost to a south country of the breakdown of cooperation is given by:

$$
\begin{aligned}
& C_{s}(\Phi)=w_{s}^{F}(t=0)-w_{s}(\Phi) \\
& =-B_{s}(\Phi)+\left[\sum \pi_{s z}\left(t_{z}^{\phi}=0\right)-\sum \pi_{s z}\left(t_{z}^{\phi}\right)\right] \\
& =\frac{[13 \alpha-62 c]\lceil 3 \alpha-2 c]}{800}, \text { where } z \neq s .
\end{aligned}
$$


The lower the production cost of its trading partner, the smaller is the increase in export profits enjoyed by a country due to the trade liberalization undertaken by its partners, and the larger is the loss in local profits suffered by the domestic firm due to its own trade liberalization. As a result, cost of defection to a country depends negatively (positively) on its own (rivals') cost:

$$
\frac{\partial C_{s}(\Phi)}{\partial c}<0
$$

This result suggests that when south firms are sufficiently high cost relative to north firm, cost of defection may even become negative:

$$
C_{s}(\Phi) \leq 0 \text { iff } c \geq c^{c r}=\frac{13 a}{62}
$$

Since benefit of defection is always positive for south countries, it is immediate from (21) that, when $c \geq c^{c r}$ holds, cooperation over free trade is never sustainable. That is, there is always an incentive for south countries to defect in this case.

On the other hand, cost of defection is always positive for the north country and gets larger as the cost asymmetry between the two regions increases:

$$
\begin{aligned}
& C_{n}(\Phi)=w_{n}^{F}(t=0)-w_{n}(\Phi) \\
& =-B_{n}(\Phi)+\left[\sum \pi_{n z}\left(t_{z}=0\right)-\sum \pi_{n z}\left(t_{z}=t_{z}^{\phi}\right)\right] \\
& =\frac{[13 \alpha+98 c\rceil[3 \alpha-2 c]}{800}, \text { where } z \neq n .
\end{aligned}
$$

and

$$
\frac{\partial C_{n}(\Phi)}{\partial c}>0
$$

More importantly, the per period cost of the breakdown of cooperation to a south country is lower than that to a north country:

$$
C_{s}(\Phi) \leq C_{n}(\Phi)
$$

For cooperation to be sustainable, the current benefit of defection must be less than the discounted life-time cost of defection for each country. In other words, the incentive compatibility (IC) constraint must hold for each country as follows: 


$$
B_{i}(\Phi) \leq \frac{\delta}{1-\delta} C_{i}(\Phi) \text { for all } i
$$

where $\partial$ denotes the discount factor and $\frac{\delta}{I-\delta} c_{i}(\Phi)$ measures the trade war's cost to each country under $(\{\Phi\})$. For each country, the critical discount factor, $\delta_{i}^{\phi}$, above which cooperation over free trade is self-enforcing is obtained when $B_{i}(\Phi)=$ $C_{i}(\Phi)$ holds. From the expressions $(17),(18)$, and $(24)$, the following is immediate (see figure 2):

Proposition 2: Under $(\{\Phi\})$, the range of discount factors above which north country is willing to cooperate over free trade is larger than that above which south countries are willing to cooperate. It implies that: $\delta_{s}^{\phi} \geq \delta_{n}^{\phi}$. Thus, multilateral cooperation over free trade is sustainable if and only if $\delta \geq \delta_{s}^{\phi}$.

Figure 2

Critical Discount factors Under No Agreement $(\alpha=1)$

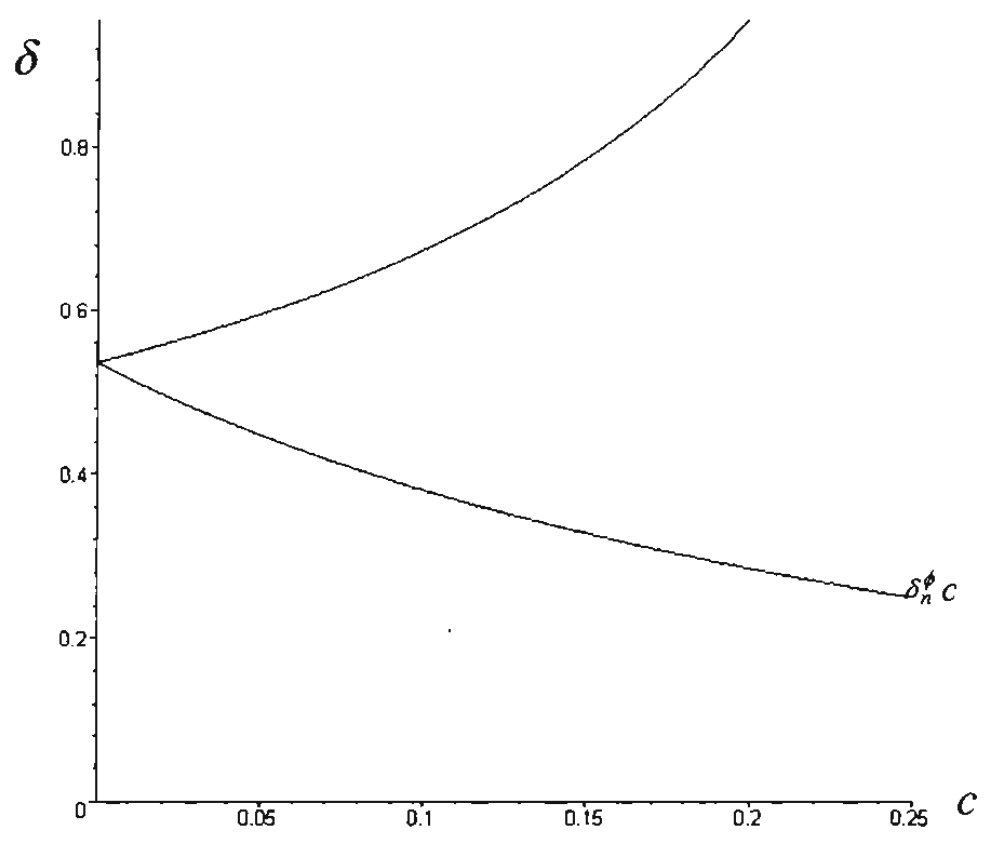

The above proposition suggests that since the benefit of defection is the same while the cost of defection is smaller for south countries relative to the north country, the critical discount factor above which south countries are willing to cooperate over free trade binds for the sustainability of multilateral cooperation over free trade. 


\section{Tariff Cooperation over Free Trade under ( $\{S\})$}

Now, we consider how the formation of a south-south CU alters incentives for multilateral tariff cooperation. To this end, we discuss how the costs and benefits of multilateral cooperation for all countries change. It is straightforward to argue that when countries cooperate over free trade, the per period welfare of the north country stays the same under $(\{S\})$ as in (15) under $(\{\Phi\})$. Therefore, the benefit of defection from cooperation for the north country remains the same under $(\{\Phi\})$ and $(\{S\})$.

Next, consider the cost of the defection of the north country. When cooperation breaks down, from the next period on, the north country responds by raising its tariff on imports from south countries from zero to $t_{n}^{\phi}$ as under $(\{\Phi\})$. In contrast, north country faces $t_{s}^{\mathcal{S}}$ (instead of $t_{s}^{\phi}$ ) in the south countries that abolish tariffs between each other. It follows immediately from the second part of the proposition 1 that:

Lemma 1: The per period cost to a north country of the breakdown of cooperation is higher under $(\{\mathrm{S}\})$ than under $(\{\Phi\})$, while the benefit of defection stays the same under these two regimes.

The above lemma implies that a south-south CU makes north countries more willing to cooperate multilaterally over free trade. Next, we consider the incentives of south countries for multilateral tariff cooperation: Note that, by the nature of the institution, defection from cooperation by a $\mathrm{CU}$ involves defection by both members. In the following discussion, the welfare per $\mathrm{CU}$ member is considered.

Let $w_{s}^{D}\left(t_{s}^{s}, t_{z}^{s}=0\right)$ denote the welfare of a south country that defects from zero tariff to its optimal tariff $t_{s}^{S}$ under ( $\left.\{S\}\right)$ :

$$
w_{s}^{D}\left(t_{s}^{S}, t_{z}^{S}=0\right) \equiv S_{s}\left(t_{s}^{S}\right)+\pi_{s s}\left(t_{s}^{S}\right)+\pi_{s n}\left(t_{n}^{S}=0\right)
$$

Thus, one period benefit from defection for south countries under $(\{S\})$ equals

$$
\begin{aligned}
& B s(S)=w_{s}^{D}\left(t_{s}^{S}, t_{\bar{z}}^{S}=0\right)-w_{s}^{F}(t=0) \\
& =\left[S_{s}\left(t_{s}^{S}\right)-S_{s}\left(t_{s}^{S}=0\right)\right]+\left[\pi_{s \cdot \bar{s}}\left(t_{s}^{S}\right)-\pi_{s \bar{s}}\left(t_{s}^{S}=0\right)\right] \\
& =\frac{[5 \alpha+2 c]^{2}}{608}>0, \text { if } c<\frac{7 \alpha}{58} \\
& =\frac{[3 \alpha-2 c][43 \alpha+78]^{2}}{3200}>0, \text { if } c \geq \frac{7 \alpha}{58} .
\end{aligned}
$$

On the other hand, one period cost of defection to south countries under ( $\{\mathrm{S}\})$ is given by: 


$$
\begin{aligned}
& C_{s}(S)=w_{s}^{F}(t=0)-w_{s}(S) \\
& =-B_{s}(S)+\left[\sum \pi_{s n}\left(t_{n}^{s}=0\right)-\sum \pi_{s n}\left(t_{n}^{S}\right)\right] .
\end{aligned}
$$

The first part of proposition 1 implies that the cost of defection is unambiguously lower under ( $\{S\})$ relative to $(\{\Phi\})$ and gets negative when south firms are sufficiently high cost (multilateral cooperation is never sustainable). Similar to the analysis under ( $\{\boldsymbol{\Phi}\})$, the incentive compatibility (IC) constraint must hold for each country for multilateral cooperation to be sustainable:

$$
B_{i}(S) \leq \frac{\delta}{1-\delta} C_{i}(S) \text { for all } i .
$$

Let $\delta_{i}^{s}$ denote the critical discount factor above which cooperation is selfenforcing for country $i$ under $(\{\mathrm{S}\})$. The following result is depicted in figure 3:

Proposition 3: Under ( $\{\mathrm{S}\})$, the range of discount factors above which north country is willing to cooperate over free trade is larger than that above which south countries are willing to cooperate. It implies that: $\delta_{s}^{s} \geq \delta_{n}^{s}$. Thus, multilateral cooperation over free trade is sustainable if and only if: $\delta \geq \delta_{s}^{s}$.

\section{Figure 3}

\section{Critical Discount Factors under South-South CU $(a=1)$}

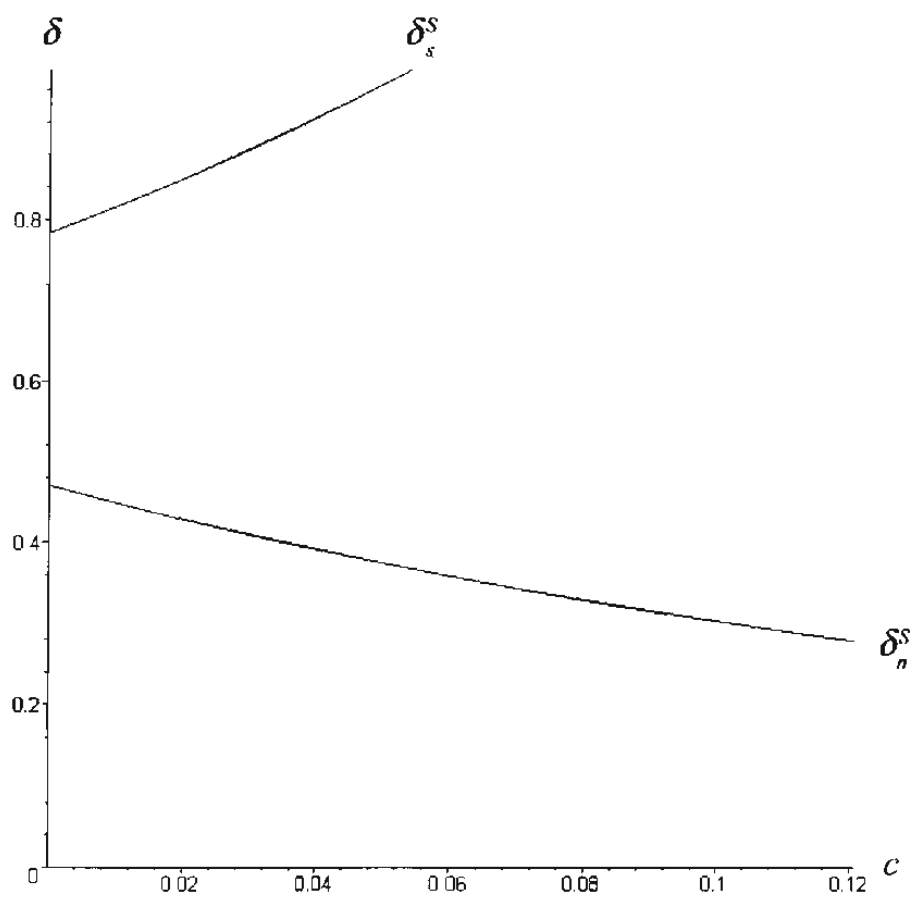


The above proposition has a similar implication as Proposition 2 in the sense that south countries' choices are binding for the sustainability of multilateral cooperation. Next, we ask whether south-south $\mathrm{CU}$ makes multilateral cooperation over free trade easier to sustain or not. To this end, figure 4 compares $\delta_{s}^{\phi}$ and $\delta_{s}^{\text {s. }}$.

Figure 4

Sustainability of Multilateral Cooperation $(\alpha=1)$

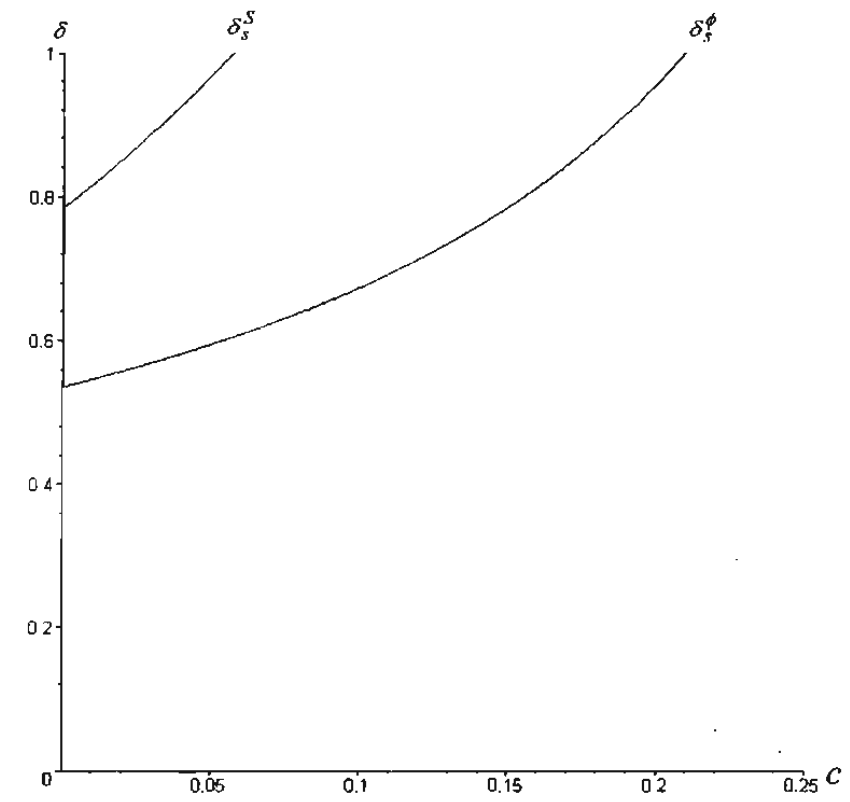

Proposition 4: Multilateral cooperation over free trade is harder to sustain under $(\{\mathrm{S}\})$ relative to $(\{\boldsymbol{\Phi}\}): \delta_{s}^{S}>\delta_{s}^{\phi}$.

The major implication of proposition 1 and proposition 4 is that when south firms are sufficiently high cost relative to north firms, the formation of a south-south CU not only reduces world welfare statically via trade diversion but also makes multilateral cooperation over free trade harder to sustain. These two results suggest that the concerns regarding the impact of south-south agreements on world welfare and the prospect of global free trade are legitimate.

\section{Conclusion}

Over the last few decades, the proliferation of PTAs has been the visible trend in the international trading system. According to the WTO, on an average, each country belongs to six PTAs and Mongolia is the only country that does not belong to a PTA. Jagdish Bhagwati (1991) famously raised concern about the potential adverse effects of the pursuit of PTAs on the pattern of tariffs, welfare, and the prospect 
of multilateral trade liberalization. His work led to a rich body of research that has examined the implications of preferential trade liberalization along several fronts. Since Jacob Viner's (1950) classic analysis, the static and dynamic distortions created by preferential trade liberalization have received substantial attention from economists and policy-makers alike. The net welfare effect of a PTA depends upon the relative dominance of the trade creation effects and the trade diversion effects of the PTAs. Since south member countries would substitute efficient imports from non-member north countries with less efficient imports from south partners, there have been widespread concerns over the welfare implications of south-south PTAs.

This paper addresses two interrelated questions: What are the static implications of a south-south PTA on the pattern of tariffs and the welfare of the PTA member countries and the world when PTA is in the form of a customs union? Do these agreements facilitate multilateral cooperation over free trade dynamically? These questions are important since the number of PTAs among developing countries has increased dramatically over the last two decades. We show that south countries always have incentives to form a CU among themselves, under which the north country is always worse off relative to no agreement. More importantly, when the degree of cost asymmetry between developed and developing countries is sufficiently high, the concerns regarding the adverse impact of such agreements on the world welfare are legitimate. We further show that the multilateral cooperation over free trade is less likely to be sustainable under a south-south customs union relative to no agreement.

\section{Notes}

1. The MFN clause states that: "Under the WTO agreements, countries cannot normally discriminate between their trading partners. Grant someone a special favour (such as a lower customs duty rate for one of their products) and you have to do the same for all other WTO members. This sounds like a contradiction. It suggests special treatment, but in the WTO it actually means non-discrimination - treating virtually everyone equally ... . Each member treats all the other members equally as "most-favoured" trading partners. If a country improves the benefits that it gives to one trading partner, it has to give the same "best" treatment to all the other WTO members so that they all remain "most-favoured"'(WTO webpage: http://www.wto. org/english/thewto_e/whatis_e/tif_e/fact2_e.htm\#seebox)

2. To minimize the potential harmful effects of PTAs, Article XXIV requires that: (i) a PTA must cover almost all trade between its members; (ii) PTA members must 
fully eliminate tariffs and other trade restrictions on each other; and (iii) they should not raise tariffs (or any other trade restrictions) on non-members.

3. In a similar set-up, Das and Ghosh (2006) employ an endogenous coalition formation model to provide a rationale for why trading blocs among similar countries may arise as an equilibrium phenomenon.

4. Note that, in order to guarantee positive output levels for the south firms in the north countryís market, we assume that $c \leq \frac{\alpha}{4}$ holds.

5. See Hoekman and Kosetcki (2001) for an extended discussion of Article XXIV.

6 . For detailed proof of the propositions, the readers may contact the corresponding author.

\section{References}

Bagwell, K., \& Staiger, R. W. (1997a, February). Multilateral cooperation during the formation of customs unions. Journal of International Economics, 42, 91-123.

Bagwell, K., \& Staiger, R. W. (1997b). Multilateral cooperation during the formation of free trade areas. International Economic Review, 38, 291-319.

Bagwell, K., \& Staiger, R. W. (1998). Will preferential agreements undermine the multilateral trading system? Economic Journal, 108, 1162-1182.

Bhagwati, J. (1991). The world trading system at risk. Princeton, NJ: Princeton University Press.

Bhagwati, J. \& Panagariya, A. (1996). Preferential trade areas and multilateralism: Strangers, friends or foes? In Bhagwati, Jagdish, \& A. Panagariya (Eds), The Economics of Preferential Trade Agreements (pp. 83-100). Washington: AEI Press.Bond, E. W., Syropoulos, C., \& Winters, L. A. (2001). Deepening of regional integration and multilateral trade agreements. Journal of International Economics, 53, 335-362.

Das, S., \& Ghosh, S. (2006). Endogenous trading bloc formation in a north-south global economy. Canadian Journal of Economics, 39(3), 809-830.

Grossman, G. M., \& Helpman, E. (1995). The politics of free-trade agreements. American Economic Review, 85, 667-690.

Ornelas, E. (2007). Exchanging market access at the outsiders' expense: The case of customs unions. Canadian Journal of Economics, 40(1), 207-224.

Ray, D. (1998). Development Economics. Oxford Press.

Riezman, R. (1991). Dynamic tariffs with asymmetric information. Journal of International Economics, 30, 267-283. 
Saggi, K. (2006). Preferential trade agreements and multilateral tariff cooperation. International Economic Review, 47, 29-57.

Schiff, M., \& Winters, L. A. (2003) Regional Integration and Development. World Bank and Oxford University Press.

Stiglitz, J. (2003). Global trade agreements are at a dead end. New Perspectives Quarterly.

Viner, J. (1950). The Custom Union Issue. New York: Carnegie Endowment for International Peace.

World Bank. (2009). Regional trade agreements. Retrieved from http://www.wto. org/english/tratop_e/region_e/region_e.htm

Biographical Sketch of Authors

Hiranya K. Nath is an Associate Professor of Economics at Sam Houston State University. He has published on inflation and relative price behavior, the growth of transition economies of Central and Eastern Europe, the growth of Bangladesh, and information economy in refereed journals including Applied Economics, Applied Economics Letters, Applied Financial Economics Letters, California Management Review, Comparative Economic Studies, Economics Letters, Journal of International Trade \& Economic Development, Journal of Macroeconomics, Journal of Money, Credit and Banking, and Review of Development Economics. He earned his Ph.D. in Economics from Southern Methodist University, Dallas (TX).

Halis M. Yildiz is an Associate Professor of Economics at Ryerson University, Toronto, Canada. He has published on international trade policy, foreign direct investment, trade and environmental policy in reputed journals like Canadian Journal of Economics, Economics Letters, Indian Growth and Development Review, International Economic Journal, International Review of Economics and Finance, Journal of Environmental Economics and Management, Journal of International Economics, Journal of International Trade \& Economic Development, and Review of International Economics. He holds a Ph.D. in Economics from Southern Methodist University, Dallas (TX). 
